\title{
Convergence theorems for uniformly quasi- $\phi$-asymptotically nonexpansive mappings, generalized equilibrium problems, and variational inequalities
}

\author{
Siwaporn Saewan ${ }^{1}$ and Poom Kumam ${ }^{1,2^{*}}$
}

\section{* Correspondence: poom. kum@kmutt.ac.th \\ ${ }^{1}$ Department of Mathematics, Faculty of Science, King Mongkut's University of Technology Thonburi (KMUTT) Bangmod, Bangkok 10140, Thailand \\ Full list of author information is available at the end of the article}

\begin{abstract}
In this article, we introduce an iterative algorithm for finding a common element of the set of common fixed points of an infinite family of closed and uniformly quasi$\phi$-asymptotically nonexpansive mappings, the set of the variational inequality for an $\alpha$-inverse-strongly monotone operator, and the set of solutions of the generalized equilibrium problems. We obtain a strong convergence theorem for the sequences generated by this process in a 2-uniformly convex and uniformly smooth Banach space. The results presented in this article improve and extend the recent results of Zegeye [Nonlinear Anal. 72, 2136-2146 (2010)], Wattanawitoon and Kumam [Nonlinear Anal. Hybrid Syst. 3(1), 11-20 (2009)] and many others.
\end{abstract}

2000 MSC: 47H05, 47H09, 47H10.

Keywords: iterative algorithms, inverse-strongly monotone operator, variational inequality, generalized equilibrium problem, uniformly quasi- $\phi$-asymptotically nonexpansive mapping

\section{Introduction and preliminaries}

Let $C$ be a nonempty closed convex subset of a real Banach space $E$ with $\|\cdot\|$ and $E^{*}$ the dual space of $E$. Recall that a mapping $T: C \rightarrow C$ is said to be L-Lipschitz continuous if $\|$ $T x-T y\|\leq L\| x-y \|, \forall x, y \in C$, and a mapping $T$ is said to be nonexpansive if $\|T x-T y\|$ $\leq\|x-y\|, \forall x, y \in C$. A point $x \in C$ is a fixed point of $T$ provided $T x=x$. Denote by $F(T)$ the set of fixed points of $T$; that is, $F(T)=\{x \in C: T x=x\}$. Let $A: C \rightarrow E^{*}$ be a mapping. Then, $A$ is called

(i) monotone if

$$
\langle A x-A y, x-y\rangle \geq 0, \quad \forall x, y \in C,
$$

(ii) $\alpha$-inverse-strongly monotone if there exists a constant $\alpha>0$ such that

$$
\langle A x-A y, x-y\rangle \geq \alpha\|A x-A y\|^{2}, \quad \forall x, y \in C .
$$

Remark 1.1. It is easy to see that an $\alpha$-inverse-strongly monotone is monotone and $\frac{1}{\alpha}$-Lipschitz continuous. 
Let $f$ be a bifunction of $C \times C$ into $\mathbb{R}$ and $B: C \rightarrow E^{*}$ be a monotone mapping. The generalized equilibrium problem, denoted by GEP, is to find $x \in C$ such that

$$
f(x, y)+\langle B x, y-x\rangle \geq 0, \quad \forall y \in C .
$$

The set of solutions for the problem (1.1) is denoted by $\operatorname{GEP}(f, B)$, that is,

$$
\operatorname{GEP}(f, B):=\{x \in C: f(x, y)+\langle B x, y-x\rangle \geq 0, \forall y \in C\}
$$

If $B \equiv 0$, the problem (1.1) reduce into the equilibrium problem for $f$, denoted by $E P$ $(f)$, is to find $x \in C$ such that

$$
f(x, y) \geq 0, \quad \forall y \in C .
$$

If $f \equiv 0$, the problem (1.1) reduce into the classical variational inequality problem, denoted by $V I(B, C)$, is to find $x^{*} \in C$ such that

$$
\left\langle B x^{*}, y-x^{*}\right\rangle \geq 0, \quad \forall y \in C \text {. }
$$

The above formulation (1.1) is more general than equilibrium problem (1.2) and cover monotone inclusion problems, saddle point problems, variational inequality problems, minimization problems, vector equilibrium problems, and Nash equilibria in noncooperative games. In addition, there are several other problems, for example, the complementarity problem, fixed point problem, and optimization problem, which can also be written in the form of an $\operatorname{GEP}(f, B)$. In other words, the $E P(f)$ is an unifying model for several problems arising in physics, engineering, science, optimization, economics, etc. In the last two decades, many articles have appeared in the literature on the existence of solutions of $E P(f)$; see, for example, [1,2] and references therein. Some solution methods have been proposed to solve the $\operatorname{GEP}(f, B)$ and $E P(f)$; see, for example, $[1,3-13]$ and references therein.

Consider the functional defined by

$$
\phi(x, y)=\|x\|^{2}-2\langle x, J y\rangle+\|y\|^{2}, \quad \forall x, y \in E .
$$

As well known that if $C$ is a nonempty closed convex subset of a Hilbert space $H$ and $P_{C}: H \rightarrow C$ is the metric projection of $H$ onto $C$, then $P_{C}$ is nonexpansive. This fact actually characterizes Hilbert spaces and consequently, it is not available in more general Banach spaces. It is obvious from the definition of function $\phi$ that

$$
(\|x\|-\|y\|)^{2} \leq \phi(x, y) \leq(\|x\|+\|y\|)^{2}, \quad \forall x, y \in E .
$$

If $E$ is a Hilbert space, then $\phi(x, y)=\|x-y\|^{2}$, for all $x, y \in E$. On the other hand, the generalized projection [14] $\Pi_{C}: E \rightarrow C$ is a map that assigns to an arbitrary point $x$ $\in E$ the minimum point of the functional $\phi(x, y)$, that is, $\Pi_{C} x=\bar{x}$, where $\bar{x}$ is the solution to the minimization problem

$$
\phi(\bar{x}, x)=\inf _{y \in C} \phi(y, x),
$$

existence and uniqueness of the operator $\Pi_{C}$ follows from the properties of the functional $\phi(x, y)$ and strict monotonicity of the mapping $J$ (see, for example, [14-18]).

Recall that a point $p$ in $C$ is said to be an asymptotic fixed point of $T$ [19] if $C$ contains a sequence $\left\{x_{n}\right\}$ which converges weakly to $p$ such that $\lim _{n} \rightarrow_{\infty}|| x_{n}-T x_{n} \|=0$. 
The set of asymptotic fixed points of $T$ will be denoted by $\widetilde{F(T)}$. A mapping $T$ is said to be $\phi$-nonexpansive, if $\phi(T x, T y) \leq \phi(x, y)$ for $x, y \in C$.

A mapping $T$ from $C$ into itself is said to be relatively nonexpansive mapping [20-22] if

(R1) $F(T)$ is nonempty;

(R2) $\phi(p, T x) \leq \phi(p, x)$ for all $x \in C$ and $p \in F(T)$;

(R3) $\widetilde{F(T)}=F(T)$.

A mapping $T$ is said to be relatively quasi-nonexpansive (or quasi- $\phi$-nonexpansive) if the conditions (R1) and (R2) are satisfied. The asymptotic behavior of a relatively nonexpansive mapping was studied in [23-25].

A mapping $T$ is said to be quasi- $\phi$-asymptotically nonexpansive if $F(T) \neq \varnothing$ and there exists a real sequence $\left\{k_{n}\right\} \subset[1, \infty)$ with $k_{n} \rightarrow 1$ such that $\phi\left(p, T^{n} x\right) \leq k_{n \phi}(p, x)$ for all $n \geq 1 x \in C$ and $p \in F(T)$. We note that the class of relatively quasi-nonexpansive mappings is more general than the class of relatively nonexpansive mappings [23-27] which requires the strong restriction: $F(T)=\widetilde{F(T)}$.

A mapping $T$ is said to be closed if for any sequence $\left\{x_{n}\right\} \subset C$ with $x_{n} \rightarrow x$ and $T x_{n} \rightarrow y$, then $T x=y$. It is easy to know that each relatively nonexpansive mapping is closed.

A Banach space $E$ is said to be strictly convex if $\left\|\frac{x+y}{2}\right\|<1$ for all $x, y \in E$ with $\|x\|=$ $\|y\|=1$ and $x \neq y$. Let $U=\{x \in E:\|x\|=1\}$ be the unit sphere of $E$. Then, a Banach space $E$ is said to be smooth if the $\operatorname{limit}_{\lim } \rightarrow 0 \frac{\|x+t y\|-\|x\|}{t}$ exists for each $x, y \in U$. It is also said to be uniformly smooth if the limit is attained uniformly for $x, y \in U$. Let $E$ be a Banach space. The modulus of convexity of $E$ is the function $\delta:[0,2] \rightarrow[0,1]$ defined by $\delta(\varepsilon)=\inf \left\{1-\left\|\frac{x+y}{2}\right\|: x, y \in E,\|x\|=\|y\|=1,\|x-y\| \geq \varepsilon\right\}$. A Banach space $E$ is uniformly convex if and only if $\delta(\varepsilon)>0$ for all $\varepsilon \in(0,2]$. Let $p$ be a fixed real number with $p \geq 2$. A Banach space $E$ is said to be $p$-uniformly convex if there exists a constant $c>0$ such that $\delta(\varepsilon) \geq c \varepsilon^{p}$ for all $\varepsilon \in[0,2]$; see [28,29] for more details. Observe that every $p$-uniform convex is uniformly convex. One should note that no a Banach space is $p$-uniform convex for $1<p<2$. It is well known that a Hilbert space is 2 -uniformly convex, uniformly smooth. For each $p>1$, the generalized duality mapping $J_{p}: E \rightarrow 2^{E^{*}}$ is defined by $J_{p}>(x)=\left\{x^{*} \in E^{*}:\left\langle x, x^{*}\right\rangle=\|x\|^{p},\left\|x^{*}\right\|=\|x\|^{p-1}\right\}$ for all $x \in$ $E$. In particular, $J=J_{2}$ is called the normalized duality mapping. If $E$ is a Hilbert space, then $J=I$, where $I$ is the identity mapping.

Remark 1.2. If $E$ is a reflexive, strictly convex, and smooth Banach space, then for $x, y \in$ $E, \phi(x, y)=0$ if and only if $x=y$. It is sufficient to show that if $\phi(x, y)=0$, then $x=y$. From (1.4), we have $\|x\|=|| y||$. This implies that $\langle x, J y\rangle=\|x\|^{2}=\|J y\|^{2}$. From the definition of $J$, one has $J x=J y$. Therefore, we have $x=y$; see $[16,18]$ for more details.

Remark 1.3. The following basic properties can be found in Cioranescu [16].

(i) If $E$ is a uniformly smooth Banach space, then $J$ is uniformly continuous on each bounded subset of $E$.

(ii) If $E$ is a reflexive and strictly convex Banach space, then $J^{-1}$ is norm-weak*continuous.

(iii) If $E$ is a smooth, strictly convex, and reflexive Banach space, then the normalized duality mapping $J: E \rightarrow 2^{E^{*}}$ is single-valued, one-to-one, and onto.

(iv) A Banach space $E$ is uniformly smooth if and only if $E^{*}$ is uniformly convex. 
(v) Each uniformly convex Banach space $E$ has the Kadec-Klee property, that is, for any sequence $\left\{x_{n}\right\} \subset E$, if $x_{n} \rightarrow x \in E$ and $\left\|x_{n}\right\| \rightarrow\|x\|$, then $x_{n} \rightarrow x$.

In 2004, Matsushita and Takahashi [30] introduced the following iteration: a sequence $\left\{x_{n}\right\}$ is defined by

$$
x_{n+1}=\Pi_{C} J^{-1}\left(\alpha_{n} J x_{n}+\left(1-\alpha_{n}\right) J T x_{n}\right),
$$

where the initial guess element $x_{0} \in C$ is arbitrary, $\left\{\alpha_{n}\right\}$ is a real sequence in $[0,1]$, $T$ is a relatively nonexpansive mapping, and $\Pi_{C}$ denotes the generalized projection from $E$ onto a closed convex subset $C$ of $E$. They proved that the sequence $\left\{x_{n}\right\}$ converges weakly to a fixed point of $T$. Later, in year 2005, Matsushita and Takahashi [26] proposed the following hybrid iteration method with generalized projection for relatively nonexpansive mapping $T$ in a Banach space $E$ :

$$
\left\{\begin{array}{l}
x_{0} \in C \text { chosen arbitrarily, } \\
y_{n}=J^{-1}\left(\alpha_{n} J x_{n}+\left(1-\alpha_{n}\right) J T x_{n}\right), \\
C_{n}=\left\{z \in C: \phi\left(z, y_{n}\right) \leq \phi\left(z, x_{n}\right)\right\}, \\
Q_{n}=\left\{z \in C:\left\langle x_{n}-z, J x_{0}-J x_{n}\right\rangle \geq 0\right\}, \\
x_{n+1}=\Pi_{C_{n} \cap Q_{n}} x_{0} .
\end{array}\right.
$$

They proved that $\left\{x_{n}\right\}$ converges strongly to $\Pi_{F(T)} x_{0}$, where $\Pi_{F(T)}$ is the generalized projection from $C$ onto $F(T)$.

In 2008, Iiduka and Takahashi [31] introduced the following iterative scheme for finding a solution of the variational inequality problem for an inverse-strongly monotone operator $A$ in a 2-uniformly convex and uniformly smooth Banach space $E: x_{1}=$ $x \in C$ and

$$
x_{n+1}=\Pi_{C} J^{-1}\left(J x_{n}-\lambda_{n} A x_{n}\right),
$$

for every $n=1,2,3, \ldots$, where $\Pi_{C}$ is the generalized metric projection from $E$ onto $C$, $J$ is the duality mapping from $E$ into $E^{*}$, and $\left\{\lambda_{n}\right\}$ is a sequence of positive real numbers. They proved that the sequence $\left\{x_{n}\right\}$ generated by (1.9) converges weakly to some element of $V I(A, C)$.

In [32,33], Takahashi and Zembayashi studied the problem of finding a common element of the set of fixed points of a nonexpansive mapping and the set of solutions of an equilibrium problem in the framework of Banach spaces. Wattanawitoon and Kumam [34] using the idea of Takahashi and Zembayashi [32] extend the notion from relatively nonexpansive mappings or $\phi$-nonexpansive mappings to two relatively quasinonexpansive mappings and also proved some strong convergence theorems to approximate a common fixed point of relatively quasi-nonexpansive mappings and the set of solutions of an equilibrium problem in the framework of Banach spaces.

On the other hand, the block iterative method is a method which often used by many authors to solve the convex feasibility problem (see, [11,35,36], etc.). In 2008, Plubtieng and Ungchittrakool [37] established strong convergence theorems of block iterative methods for a finite family of relatively nonexpansive mappings in a Banach space by using the hybrid method in mathematical programming. In 2010, Chang et al. [38] proposed the modified block iterative algorithm for solving the convex feasibility problems for an infinite family of closed and uniformly quasi- $\phi$-asymptotically nonexpansive mapping, they obtain the strong convergence theorems in a Banach space. 
In this article, motivated and inspired by the study of Chang et al. [38], Qin et al. [9], Takahashi and Zembayashi [32], Wattanawitoon and Kumam [34], and Zegeye [39], we introduce a new modified block hybrid projection algorithm for finding a common element of the set of the variational inequality for an $\alpha$-inverse-strongly monotone operator, the set of solutions of the generalized equilibrium problems, and the set of common fixed points of an infinite family of closed and uniformly quasi- $\phi$-asymptotically nonexpansive mappings which more general than closed quasi- $\phi$-nonexpansive mappings in the framework Banach spaces. The results presented in this article improve and generalize the main results of Chang et al. [38], Zegeye [39], Wattanawitoon and Kumam [34], and some well-known results in the literature.

\section{Basic results}

We also need the following lemmas for the proof of our main results.

Lemma 2.1. (Beauzamy [40] and $X u$ [41]). If E be a 2-uniformly convex Banach space. Then, for all $x, y \in E$, we have

$$
\|x-y\| \leq \frac{2}{c^{2}}\|J x-J y\|,
$$

where $J$ is the normalized duality mapping of $E$ and $0<c \leq 1$.

The best constant $\frac{1}{c}$ in lemma is called the p-uniformly convex constant of $E$.

Lemma 2.2. (Beauzamy [40] and Zalinescu [42]). If E be a p-uniformly convex Banach space and let $p$ be a given real number with $p \geq 2$. Then, for all $x, y \in E, j_{x} \in$ $J_{p}(x)$, and $j_{y} \in J_{p}(y)$

$$
\left\langle x-y, j_{x}-j_{y}\right\rangle \geq \frac{c^{p}}{2^{p-2} p}\|x-y\|^{p},
$$

where $J_{p}$ is the generalized duality mapping of $E$, and $\frac{1}{c}$ is the p-uniformly convexity constant of $E$.

Lemma 2.3. (Kamimura and Takahashi [17]). Let E be a uniformly convex and smooth Banach space and let $\left\{x_{n}\right\}$ and $\left\{y_{n}\right\}$ be two sequences of $E$. If $\phi\left(x_{n}, y_{n}\right) \rightarrow 0$ and either $\left\{x_{n}\right\}$ or $\left\{y_{n}\right\}$ is bounded, then $\left\|x_{n}-y_{n}\right\| \rightarrow 0$.

Lemma 2.4. (Alber [14]). Let $C$ be a nonempty closed convex subset of a smooth Banach space $E$ and $x \in E$. Then, $x_{0}=\Pi_{C} x$ if and only if

$$
\left\langle x_{0}-y, J x-J x_{0}\right\rangle \geq 0, \quad \forall y \in C .
$$

Lemma 2.5. (Alber [14]). Let $E$ be a reflexive, strictly convex, and smooth Banach space, let $C$ be a nonempty closed convex subset of $E$ and let $x \in E$. Then,

$$
\phi\left(y, \Pi_{C} x\right)+\phi\left(\Pi_{C} x, x\right) \leq \phi(y, x), \quad \forall y \in C .
$$

For solving the equilibrium problem for a bifunction $f: C \times C \rightarrow \mathbb{R}$, let us assume that $f$ satisfies the following conditions:

(A1) $f(x, x)=0$ for all $x \in C$;

(A2) $f$ is monotone, i.e., $f(x, y)+f(y, x) \leq 0$ for all $x, y \in C$;

(A3) for each $x, y, z \in C$,

$$
\lim _{t \downarrow 0} f(t z+(1-t) x, y) \leq f(x, y)
$$


(A4) for each $x \in C, y \propto f(x, y)$ is convex and lower semi-continuous.

Lemma 2.6. (Blum and Oettli [1]). Let $C$ be a closed convex subset of a smooth, strictly convex, and reflexive Banach space $E$, let $f$ be a bifunction from $C \times C$ to $\mathbb{R}$ satisfying (A1)-(A4), and let $r>0$ and $x \in E$. Then, there exists $z \in C$ such that

$$
f(z, y)+\frac{1}{r}\langle y-z, J z-J x\rangle \geq 0, \quad \forall y \in C .
$$

Replacing $x$ with $J^{-1}(J x-r B x)$, where $B$ is a monotone mapping from $C$ into $E^{*}$, then there exists $z \in C$ such that

$$
f(z, y)+\langle B z, y-z\rangle+\frac{1}{r}\langle y-z, J z-J x\rangle \geq 0, \quad \forall y \in C .
$$

Lemma 2.7. (Zegeye [39]). Let $C$ be a closed convex subset of a uniformly smooth, strictly convex, and reflexive Banach space $E$, and let $f$ be a bifunction from $C \times C$ to $\mathbb{R}$ satisfying (A1)-(A4), and let $B$ be a monotone mapping from $C$ into $E^{*}$. For $r>0$ and $\times$ $\in E$, define a mapping $T_{r}: C \rightarrow C$ as follows:

$$
T_{r} x=\left\{z \in C: f(z, y)+\langle B x, y-z\rangle+\frac{1}{r}\langle y-z, J z-J x\rangle \geq 0, \quad \forall y \in C\right\}
$$

for all $x \in C$. Then, the following hold:

(1) $T_{r}$ is single-valued;

(2) $T_{r}$ is a firmly nonexpansive-type mapping, for all $x, y \in E$,

$$
\left\langle T_{r} x-T_{r} y_{,} J T_{r} x-J T_{r} y\right\rangle \leq\left\langle T_{r} x-T_{r} y, J x-J y\right\rangle ;
$$

(3) $F\left(T_{r}\right)=G E P(f, B)$;

(4) $\operatorname{GEP}(f, B)$ is closed and convex.

Lemma 2.8. (Zegeye [39]). Let $C$ be a closed convex subset of a smooth, strictly convex, and reflexive Banach space $E$, let $f$ be a bifunction from $C \times C$ to $\mathbb{R}$ satisfying (A1)(A4), and let $B$ be a monotone mapping from $C$ into $E^{*}$. For $r>0, x \in E$, and $q \in F\left(T_{r}\right)$, we have that

$$
\phi\left(q, T_{r} x\right)+\phi\left(T_{r} x, x\right) \leq \phi(q, x) .
$$

Let $E$ be a reflexive, strictly convex, smooth Banach space and $J$ is the duality mapping from $E$ into $E^{*}$. Then, $J^{-1}$ is also single value, one-to-one, surjective, and it is the duality mapping from $E^{*}$ into $E$. We make use of the following mapping $V$ studied in Alber [14]

$$
V\left(x, x^{*}\right)=\|x\|^{2}-2\left\langle x, x^{*}\right\rangle+\left\|x^{*}\right\|^{2}
$$

for all $x \in E$ and $x^{*} \in E^{*}$, that is, $V\left(x, x^{*}\right)=\phi\left(x, J^{-1}\left(x^{*}\right)\right)$.

Lemma 2.9. (Alber [14]). Let $E$ be a reflexive, strictly convex, smooth Banach space and let $V$ be as in (2.1). Then,

$$
V\left(x, x^{*}\right)+2\left\langle J^{-1}\left(x^{*}\right)-x, y^{*}\right\rangle \leq V\left(x, x^{*}+y^{*}\right)
$$

for all $x \in E$ and $x^{*}, y^{*} \in E^{*}$.

An operator $\mathcal{M} \subset E \times E^{*}$ is said to be monotone if $\left\langle x-y, x^{*}-y^{*}\right\rangle \geq 0$ whenever ( $x$, $\left.x^{*}\right),\left(y, y^{*}\right) \in T$. We denote the set $\{x \in E: 0 \in T x\}$ by $\mathcal{M}^{-1} 0$. A monotone $\mathcal{M}$ is said to be maximal if its graph $G(\mathcal{M})=\{(x, y): y \in \mathcal{M} x\}$ is not property contained in the 
graph of any other monotone operator. If $\mathcal{M}$ is maximal monotone, then the solution set $\mathcal{M}^{-1} 0$ is closed and convex. Let $E$ be a reflexive, strictly convex, and smooth Banach space, it is known that $\mathcal{M}$ is a maximal monotone if and only if $R(J+r \mathcal{M})=E^{*}$ for all $r>0$. Define the resolvent of $\mathcal{M}$ by $J_{r} x=x_{r}$. In other words, $J_{r}=(J+r \mathcal{M})^{-1} J$ for all $r>0 . J_{r}$ is a single-valued mapping from $E$ to $D(\mathcal{M})$. Also, $\mathcal{M}^{-1}(0)=F\left(J_{r}\right)$ for all $r>0$, where $F\left(J_{r}\right)$ is the set of all fixed points of $J_{r}$. Define, for $r>0$, the Yosida approximation of $\mathcal{M}$ by $\mathcal{M}_{r}=\left(J-J J_{r}\right) / r$. We know that $\mathcal{M}_{r} x \in \mathcal{M}\left(J_{r} x\right)$ for all $r>0$ and $x \in E$.

Let $A$ be an inverse-strongly monotone mapping of $C$ into $E^{*}$ which is said to be hemicontinuous if for all $x, y \in C$, the mapping $F$ of $[0,1]$ into $E^{*}$, defined by $F(t)=A$ $(t x+(1-t) y)$, is continuous with respect to the weak* topology of $E^{*}$. We define by $N_{C}$ (v) the normal cone for $C$ at a point $v \in C$, that is,

$$
N_{C}(v)=\left\{x^{*} \in E^{*}:\left\langle v-y, x^{*}\right\rangle \geq 0, \forall y \in C\right\} .
$$

Lemma 2.10. (Rockafellar [43]). Let $C$ be a nonempty, closed convex subset of a Banach space $E$, and $A$ is a monotone, hemicontinuous operator of $C$ into $E^{*}$. Let $\mathcal{M} \subset E \times E^{*}$ be an operator defined as follows:

$$
\mathcal{M} v=\left\{\begin{array}{l}
\text { Av }+N_{C}(v), \quad v \in C ; \\
\emptyset \text { otherwise. }
\end{array}\right.
$$

Then, Mis maximal monotone and $\mathcal{M}^{-1} 0=\operatorname{VI}(A, C)$.

Lemma 2.11. (Chang et al. [38]). Let E be a uniformly convex Banach space, $r>0$ be a positive number and $B_{r}(0)$ be a closed ball of $E$. Then, for any given sequence $\left\{x_{i}\right\}_{i=1}^{\infty} \subset B_{r}(0)$ and for any given sequence $\left\{\lambda_{i}\right\}_{i=1}^{\infty}$ of positive number with $\sum_{n=1}^{\infty} \lambda_{n}=1$, there exists a continuous, strictly increasing, and convex function $g:[0,2 r) \rightarrow[0, \infty)$ with $g(0)=0$ such that, for any positive integer $i, j$ with $i<j$,

$$
\left\|\sum_{n=1}^{\infty} \lambda_{n} x_{n}\right\|^{2} \leq \sum_{n=1}^{\infty} \lambda_{n}\left\|x_{n}\right\|^{2}-\lambda_{i} \lambda_{j} g\left(\left\|x_{i}-x_{j}\right\|\right) .
$$

Lemma 2.12. (Chang et al. [38]). Let E be a real uniformly smooth and strictly convex Banach space, and $C$ be a nonempty closed convex subset of $E$. Let $T: C \rightarrow C$ be a closed and quasi- $\phi$-asymptotically nonexpansive mapping with a sequence $\left\{k_{n}\right\} \subset[1, \infty), k_{n} \rightarrow 1$. Then, $F(T)$ is a closed convex subset of $C$.

\section{Main results}

Definition 3.1. (Chang et al. [38]) (1) Let $\left\{S_{i}\right\}_{i=1}^{\infty}: C \rightarrow C$ be a sequence of mapping. $\left\{S_{i}\right\}_{i=1}^{\infty}$ is said to be a family of uniformly quasi- $\phi$-asymptotically nonexpansive mappings, if $\mathcal{F}:=\cap_{n=1}^{\infty} F\left(S_{n}\right) \neq \emptyset$, and there exists a sequence $\left\{k_{n}\right\} \subset[1, \infty)$ with $k_{n} \rightarrow 1$ such that for each $i \geq 1$

$$
\phi\left(p, S_{i}^{n} x\right) \leq k_{n} \phi(p, x), \quad \forall p \in \mathcal{F}, \quad x \in C, \quad \forall n \geq 1 .
$$

(2) A mapping $S: C \rightarrow C$ is said to be uniformly L-Lipschitz continuous, if there exists a constant $L>0$ such that

$$
\left\|S^{n} x-S^{n} y\right\| \leq L\|x-y\|, \quad \forall x, y \in C .
$$

In this section, we prove the new convergence theorems for finding the set of solutions of a general equilibrium problems, the common fixed point set of a family of 
closed and uniformly quasi- $\phi$-asymptotically nonexpansive mappings, and the solution set of variational inequalities for an $\alpha$-inverse strongly monotone mapping in a 2-uniformly convex and uniformly smooth Banach space.

Theorem 3.2. Let $C$ be a nonempty closed and convex subset of a 2-uniformly convex and uniformly smooth Banach space E. Let $A$ be an $\alpha$-inverse-strongly monotone mapping of $C$ into $E^{*}$ satisfying $\|A y\| \leq\|A y-A u\|, \forall y \in C$ and $u \in V I(A, C) \neq \varnothing$. Let $f$ be a bifunction from $C \times C$ to $\mathbb{R}$ satisfying (A1)-(A4) and $B$ be a continuous monotone mapping of $C$ into $E^{*}$. Let $\left\{S_{i}\right\}_{i=1}^{\infty}: C \rightarrow$ Cbe an infinite family of closed uniformly $L_{i^{-}}$ Lipschitz continuous and uniformly quasi- $\phi$-asymptotically nonexpansive mappings with a sequence $\left\{k_{n}\right\} \subset[1, \infty), k_{n} \rightarrow 1$ such that $F:=\cap_{i=1}^{\infty} F\left(S_{i}\right) \cap \operatorname{GEP}(f, B) \cap V I(A, C)$ is a nonempty and bounded subset in $C$. For an initial point $x_{0} \in E$ with $x_{1}=\Pi_{C_{1}} x_{0}$ and $C_{1}=C$, we define the sequence $\left\{x_{n}\right\}$ as follows:

$$
\left\{\begin{array}{l}
z_{n}=\Pi_{C} J^{-1}\left(J x_{n}-\lambda_{n} A x_{n}\right), \\
y_{n}=J^{-1}\left(\alpha_{n, 0} J x_{n}+\sum_{i=1}^{\infty} \alpha_{n, i} J S_{i}^{n} z_{n}\right), \\
f\left(u_{n}, y\right)+\left\langle B y_{n}, y-u_{n}\right\rangle+\frac{1}{r_{n}}\left\langle y-u_{n}, J u_{n}-J y_{n}\right\rangle \geq 0, \quad \forall y \in C, \\
C_{n+1}=\left\{z \in C_{n}: \phi\left(z, u_{n}\right) \leq \phi\left(z, x_{n}\right)+\zeta_{n}\right\} \\
x_{n+1}=\Pi_{C_{n+1}} x_{0}, \quad \forall n \geq 1,
\end{array}\right.
$$

where $\zeta_{n}=\sup _{q \in F}\left(k_{n}-1\right) \phi\left(q, x_{n}\right),\left\{\alpha_{n, i}\right\}$ is sequence in $[0,1],\left\{r_{n}\right\} \subset[d, \infty)$ for some $d$ $>0$ and $\left\{\lambda_{n}\right\} \subset[a, b]$ for some $a, b$ with $0<a<b<c^{2} \alpha / 2$, where $\frac{1}{c}$ is the 2-uniformly convexity constant of $E$. If $\sum_{i=0}^{\infty} \alpha_{n, i}=1$ for all $n \geq 0$ and $\lim _{\inf } f_{n \rightarrow \infty} \alpha_{n, 0} \alpha_{n, i}>0$ for all $i \geq$ 1 , then $\left\{x_{n}\right\}$ converges strongly to $p \in F$, where $p=\Pi_{F} x_{0}$.

Proof. We first show that $C_{n+1}$ is closed and convex for each $n \geq 0$. Clearly, $C_{1}=C$ is closed and convex. Suppose that $C_{n}$ is closed and convex for each $n \in \mathbb{N}$. Since for any $z \in C_{n}$, we know that $\phi\left(z, u_{n}\right) \leq \phi\left(z, x_{n}\right)+\zeta_{n}$ is equivalent to $2\left\langle z, J x_{n}-J u_{n}\right\rangle \leq \|$ $x_{n}\left\|^{2}-\right\| u_{n} \|^{2}+\zeta_{n}$. Hence, $C_{n+1}$ is closed and convex. Next, we show that $F \subset C_{n}$ for all $n \geq 0$. Indeed, put $u_{n}=T_{r_{n}} y_{n}$ for all $n \geq 0$. On the other hand, from Lemma 2.7, one has $T_{r_{n}}$ is relatively quasi-nonexpansive mappings and $F \subset C_{1}=C$. Suppose $F \subset C_{n}$ for $n \in \mathbb{N}$, by the convexity of $\|\cdot\|^{2}$, property of $\phi$, Lemma 2.11 and by uniformly quasi$\phi$-asymptotically nonexpansive of $S_{n}$ for each $q \in F \subset C_{n}$, we have

$$
\begin{aligned}
\phi\left(q, u_{n}\right)= & \phi\left(q, T_{r_{n}} y_{n}\right) \\
\leq & \phi\left(q, y_{n}\right) \\
= & \phi\left(q, J^{-1}\left(\alpha_{n, 0} J x_{n}+\sum_{i=1}^{\infty} \alpha_{n, i} J S_{i}^{n} z_{n}\right)\right) \\
= & \|q\|^{2}-2\left\langle q, \alpha_{n, 0} J x_{n}+\sum_{i=1}^{\infty} \alpha_{n, i} J S_{i}^{n} z_{n}\right\rangle+\left\|\alpha_{n, 0} J x_{n}+\sum_{i=1}^{\infty} \alpha_{n, j} J S_{i}^{n} z_{n}\right\|^{2} \\
= & \left.\|q\|^{2}-2 \alpha_{n, 0}\left\langle q, J x_{n}\right\rangle-2 \sum_{i=1}^{\infty} \alpha_{n, i}\left\langle q, J S_{i}^{n} z_{n}\right\rangle+\| \alpha_{n, 0} J x_{n}+\sum_{i=1}^{\infty} \alpha_{n, j} J S_{i}^{n} z_{n}\right)\|\|^{2} \\
\leq & \|q\|^{2}-2 \alpha_{n, 0}\left\langle q, J x_{n}\right\rangle-2 \sum_{i=1}^{\infty} \alpha_{n, i}\left\langle q, J S_{i}^{n} z_{n}\right\rangle+\alpha_{n, 0}\left\|J x_{n}\right\|^{2}+\sum_{i=1}^{\infty} \alpha_{n, i}\left\|J S_{i}^{n} z_{n}\right\|^{2} \\
& -\alpha_{n, 0} \alpha_{n, j} g\left\|J z_{n}-J S_{j}^{n} z_{n}\right\| \\
= & \|q\|^{2}-2 \alpha_{n, 0}\left\langle q, J x_{n}\right\rangle+\alpha_{n, 0}\left\|J x_{n}\right\|^{2}-2 \sum_{i=1}^{\infty} \alpha_{n, i}\left\langle q, J S_{i}^{n} z_{n}\right\rangle \\
& +\sum_{i=1}^{\infty} \alpha_{n, i}\left\|J S_{i}^{n} z_{n}\right\|^{2}-\alpha_{n, 0} \alpha_{n, j} g\left\|J z_{n}-J S_{j}^{n} z_{n}\right\| \\
= & \alpha_{n, 0} \phi\left(q, x_{n}\right)+\sum_{i=1}^{\infty} \alpha_{n, i} \phi\left(q, S_{i}^{n} z_{n}\right)-\alpha_{n, 0} \alpha_{n, j} g\left\|J z_{n}-J S_{j}^{n} z_{n}\right\| \\
\leq & \alpha_{n, 0} \phi\left(q, x_{n}\right)+\sum_{i=1}^{\infty} \alpha_{n, i} k_{n} \phi\left(q, z_{n}\right)-\alpha_{n, 0} \alpha_{n, j} g\left\|J z_{n}-J S_{j}^{n} z_{n}\right\| .
\end{aligned}
$$


It follows from Lemma 2.9 that

$$
\begin{aligned}
\phi\left(q, z_{n}\right) & =\phi\left(q, \Pi_{C} J^{-1}\left(J x_{n}-\lambda_{n} A x_{n}\right)\right) \\
& \leq \phi\left(q, J^{-1}\left(J x_{n}-\lambda_{n} A x_{n}\right)\right) \\
& =V\left(q, J x_{n}-\lambda_{n} A x_{n}\right) \\
& \leq V\left(q,\left(J x_{n}-\lambda_{n} A x_{n}\right)+\lambda_{n} A x_{n}\right)-2\left\langle J^{-1}\left(J x_{n}-\lambda_{n} A x_{n}\right)-q, \lambda_{n} A x_{n}\right\rangle \\
& =V\left(q, J x_{n}\right)-2 \lambda_{n}\left\langle J^{-1}\left(J x_{n}-\lambda_{n} A x_{n}\right)-q, A x_{n}\right\rangle \\
& =\phi\left(q, x_{n}\right)-2 \lambda_{n}\left\langle x_{n}-q, A x_{n}\right\rangle+2\left\langle J^{-1}\left(J x_{n}-\lambda_{n} A x_{n}\right)-x_{n},-\lambda_{n} A x_{n}\right\rangle .
\end{aligned}
$$

Since $q \in V I(A, C)$ and $A$ is an $\alpha$-inverse-strongly monotone mapping, we have

$$
\begin{aligned}
-2 \lambda_{n}\left\langle x_{n}-q, A x_{n}\right\rangle & =-2 \lambda_{n}\left\langle x_{n}-q, A x_{n}-A q\right\rangle-2 \lambda_{n}\left\langle x_{n}-q, A q\right\rangle \\
& \leq-2 \lambda_{n}\left\langle x_{n}-q, A x_{n}-A q\right\rangle \\
& =-2 \alpha \lambda_{n}\left\|A x_{n}-A q\right\|^{2} .
\end{aligned}
$$

From Lemma 2.1 and $A$ is an $\alpha$-inverse-strongly monotone mapping, we also have

$$
\begin{aligned}
2\left\langle J^{-1}\left(J x_{n}-\lambda_{n} A x_{n}\right)-x_{n},-\lambda_{n} A x_{n}\right\rangle & =2\left\langle J^{-1}\left(J x_{n}-\lambda_{n} A x_{n}\right)-J^{-1}\left(J x_{n}\right),-\lambda_{n} A x_{n}\right\rangle \\
& \leq 2\left\|J^{-1}\left(J x_{n}-\lambda_{n} A x_{n}\right)-J^{-1}\left(J x_{n}\right)\right\|\left\|\lambda_{n} A x_{n}\right\| \\
& \leq \frac{4}{c^{2}}\left\|J J^{-1}\left(J x_{n}-\lambda_{n} A x_{n}\right)-J J^{-1}\left(J x_{n}\right)\right\|\left\|\lambda_{n} A x_{n}\right\| \\
& =\frac{4}{c^{2}}\left\|J x_{n}-\lambda_{n} A x_{n}-J x_{n}\right\|\left\|\lambda_{n} A x_{n}\right\| \\
& =\frac{4}{c^{2}}\left\|\lambda_{n} A x_{n}\right\|^{2} \\
& =\frac{4}{c^{2}} \lambda_{n}^{2}\left\|A x_{n}\right\|^{2} \\
& \leq \frac{4}{c^{2}} \lambda_{n}^{2}\left\|A x_{n}-A q\right\|^{2} .
\end{aligned}
$$

Substituting (3.6) and (3.7) into (3.5), we obtain

$$
\begin{aligned}
\phi\left(q, z_{n}\right) & \leq \phi\left(q, x_{n}\right)-2 \alpha \lambda_{n}\left\|A x_{n}-A q\right\|^{2}+\frac{4}{c^{2}} \lambda_{n}^{2}\left\|A x_{n}-A q\right\|^{2} \\
& =\phi\left(q, x_{n}\right)+2 \lambda_{n}\left(\frac{2}{c^{2}} \lambda_{n}-\alpha\right)\left\|A x_{n}-A q\right\|^{2} \\
& \leq \phi\left(q, x_{n}\right) .
\end{aligned}
$$

Substituting (3.8) into (3.4), we also have

$$
\begin{aligned}
\phi\left(q, u_{n}\right) & \leq \alpha_{n, 0} \phi\left(q, x_{n}\right)+\sum_{i=1}^{\infty} \alpha_{n, i} k_{n} \phi\left(q, x_{n}\right)-\alpha_{n, 0} \alpha_{n, j} g\left\|J z_{n}-J S_{j}^{n} z_{n}\right\| \\
& \leq \alpha_{n, 0} k_{n} \phi\left(q, x_{n}\right)+\sum_{i=1}^{\infty} \alpha_{n, i} k_{n} \phi\left(q, x_{n}\right)-\alpha_{n, 0} \alpha_{n, j} g\left\|J z_{n}-J S_{j}^{n} z_{n}\right\| \\
& \leq k_{n} \phi\left(q, x_{n}\right)-\alpha_{n, 0} \alpha_{n, j} g\left\|J z_{n}-J S_{j}^{n} z_{n}\right\| \\
& \leq \phi\left(q, x_{n}\right)+\sup _{q \in F}\left(k_{n}-1\right) \phi\left(q, x_{n}\right)-\alpha_{n, 0} \alpha_{n, j} g\left\|J z_{n}-J S_{j}^{n} z_{n}\right\| \\
& =\phi\left(q, x_{n}\right)+\zeta_{n}-\alpha_{n, 0} \alpha_{n, j} g\left\|J z_{n}-J S_{j}^{n} z_{n}\right\| \\
& \leq \phi\left(q, x_{n}\right)+\zeta_{n} .
\end{aligned}
$$

This shows that $q \in C_{n+1}$ implies that $F \subset C_{n+1}$ and hence, $F \subset C_{n}$ for all $n \geq 0$. This implies that the sequence $\left\{x_{n}\right\}$ is well defined. From definition of $C_{n+1}$ that $x_{n}=\Pi_{C_{n}} x_{0}$ and $x_{n+1}=\Pi_{C_{n+1}} x_{0} \in C_{n+1} \subset C_{n}$, we have

$$
\phi\left(x_{n}, x_{0}\right) \leq \phi\left(x_{n+1}, x_{0}\right), \quad \forall n \geq 0 .
$$


By Lemma 2.5, we get

$$
\begin{aligned}
\phi\left(x_{n}, x_{0}\right) & =\phi\left(\Pi_{C_{n}} x_{0}, x_{0}\right) \\
& \leq \phi\left(q, x_{0}\right)-\phi\left(q, x_{n}\right) \\
& \leq \phi\left(q, x_{0}\right), \quad \forall q \in F .
\end{aligned}
$$

From (3.10) and (3.11), then $\left\{\phi\left(x_{n}, x_{0}\right)\right\}$ are nondecreasing and bounded. Hence, we obtain that $\lim _{n \rightarrow \infty} \phi\left(x_{n}, x_{0}\right)$ exists. In particular, by (1.5), the sequence $\left\{\left(|| x_{n}\|-\| x_{0}||\right)^{2}\right\}$ is bounded. This implies $\left\{x_{n}\right\}$ is also bounded. Denote

$$
K=\sup _{n \geq 0}\left\{\left\|x_{n}\right\|\right\}<\infty .
$$

Moreover, by the definition of $\left\{\zeta_{n}\right\}$ and (3.12), it follows that

$$
\zeta_{n} \rightarrow 0 \quad \text { as } n \rightarrow \infty
$$

Next, we show that $\left\{x_{n}\right\}$ is a Cauchy sequence in $C$. Since $x_{m}=\Pi_{C_{m}} x_{0} \in C_{m} \subset C_{n}$, for $m>n$, by Lemma 2.5 , we have

$$
\begin{aligned}
\phi\left(x_{m}, x_{n}\right) & =\phi\left(x_{m}, \Pi_{C_{n}} x_{0}\right) \\
& \leq \phi\left(x_{m}, x_{0}\right)-\phi\left(\Pi_{C_{n}} x_{0}, x_{0}\right) \\
& =\phi\left(x_{m}, x_{0}\right)-\phi\left(x_{n}, x_{0}\right) .
\end{aligned}
$$

Since $\lim _{n \rightarrow \infty} \phi\left(x_{n}, x_{0}\right)$ exists and we taking $m, n \rightarrow \infty$, then we get $\phi\left(x_{m}, x_{n}\right) \rightarrow 0$. From Lemma 2.3, we have $\lim _{n \rightarrow \infty}\left\|x_{m}-x_{n}\right\|=0$. Thus, $\left\{x_{n}\right\}$ is a Cauchy sequence and by the completeness of $E$ and there exist a point $p \in C$ such that $x_{n} \rightarrow p$ as $n \rightarrow \infty$.

Now, we claim that $\left\|J u_{n}-J x_{n}\right\| \rightarrow 0$, as $n \rightarrow \infty$. By definition of $\Pi_{C_{n}} x_{0}$, we have

$$
\begin{aligned}
\phi\left(x_{n+1}, x_{n}\right) & =\phi\left(x_{n+1}, \Pi_{C_{n}} x_{0}\right) \\
& \leq \phi\left(x_{n+1}, x_{0}\right)-\phi\left(\Pi_{C_{n}} x_{0}, x_{0}\right) \\
& =\phi\left(x_{n+1}, x_{0}\right)-\phi\left(x_{n}, x_{0}\right) .
\end{aligned}
$$

Since $\lim _{n \rightarrow \infty} \phi\left(x_{n}, x_{0}\right)$ exists, we also have

$$
\lim _{n \rightarrow \infty} \phi\left(x_{n+1}, x_{n}\right)=0 \text {. }
$$

Again from Lemma 2.3 that

$$
\lim _{n \rightarrow \infty}\left\|x_{n+1}-x_{n}\right\|=0 .
$$

From $J$ is uniformly norm-to-norm continuous on bounded subsets of $E$, we obtain

$$
\lim _{n \rightarrow \infty}\left\|J x_{n+1}-J x_{n}\right\|=0 .
$$

Since $x_{n+1}=\Pi_{C_{n+1}} x_{0} \in C_{n+1} \subset C_{n}$ and the definition of $C_{n+1}$, we have

$$
\phi\left(x_{n+1}, u_{n}\right) \leq \phi\left(x_{n+1}, x_{n}\right)+\zeta_{n} .
$$

By (3.14) and (3.13) that

$$
\lim _{n \rightarrow \infty} \phi\left(x_{n+1}, u_{n}\right)=0 .
$$

Again applying Lemma 2.3, we have

$$
\lim _{n \rightarrow \infty}\left\|x_{n+1}-u_{n}\right\|=0 .
$$


Since

$$
\begin{aligned}
\left\|u_{n}-x_{n}\right\| & =\left\|u_{n}-x_{n+1}+x_{n+1}-x_{n}\right\| \\
& \leq\left\|u_{n}-x_{n+1}\right\|+\left\|x_{n+1}-x_{n}\right\| .
\end{aligned}
$$

It follows that

$$
\lim _{n \rightarrow \infty}\left\|u_{n}-x_{n}\right\|=0
$$

Since $J$ is uniformly norm-to-norm continuous on bounded subsets of $E$, we also have

$$
\lim _{n \rightarrow \infty}\left\|J u_{n}-J x_{n}\right\|=0
$$

Next, we will show that $p \in F:=\operatorname{GEP}(f, B) \cap\left(\cap_{i=1}^{\infty} F\left(S_{i}\right)\right) \cap V I(A, C)$.

(a) First, we show that $p \in G E P(f, B)$. From (3.4) and (3.8), we get $\phi\left(p, y_{n}\right) \leq \phi\left(p, x_{n}\right)$. By Lemma 2.8 and $u_{n}=T_{r_{n}} y_{n}$, we observe that

$$
\begin{aligned}
\phi\left(u_{n}, y_{n}\right) & =\phi\left(T_{r_{n}} y_{n}, y_{n}\right) \\
& \leq \phi\left(q, y_{n}\right)-\phi\left(q, T_{r_{n}} y_{n}\right) \\
& \leq \phi\left(q, x_{n}\right)-\phi\left(q, T_{r_{n}} y_{n}\right) \\
& =\phi\left(q, x_{n}\right)-\phi\left(q, u_{n}\right) \\
& =\|q\|^{2}-2\left\langle q, J x_{n}\right\rangle+\left\|x_{n}\right\|^{2}-\left(\|q\|^{2}-2\left\langle q, J u_{n}\right\rangle+\left\|u_{n}\right\|^{2}\right) \\
& =\left\|x_{n}\right\|^{2}-\left\|u_{n}\right\|^{2}-2\left\langle q, J x_{n}-J u_{n}\right\rangle \\
& \leq\left\|x_{n}-u_{n}\right\|\left(\left\|x_{n}\right\|+\left\|u_{n}\right\|\right)+2\|q\|\left\|J x_{n}-J u_{n}\right\| .
\end{aligned}
$$

From (3.19), (3.20), and Lemma 2.3, we have

$$
\lim _{n \rightarrow \infty}\left\|u_{n}-y_{n}\right\|=0
$$

Again since $J$ is uniformly norm-to-norm continuous, we also have

$$
\lim _{n \rightarrow \infty}\left\|J u_{n}-J y_{n}\right\|=0 .
$$

From (A2), we note that

$$
\left\langle B y_{n}, y-u_{n}\right\rangle+\frac{1}{r_{n}}\left\langle y-u_{n}, J u_{n}-J y_{n}\right\rangle \geq-f\left(u_{n}, y\right) \geq f\left(y, u_{n}\right), \quad \forall y \in C,
$$

and hence

$$
\left\langle B y_{n}, y-u_{n}\right\rangle+\left\langle y-u_{n}, \frac{J u_{n}-J y_{n}}{r_{n}}\right\rangle \geq f\left(y, u_{n}\right), \quad \forall y \in C .
$$

For $t$ with $0<t<1$ and $y \in C$, let $y_{t}=t y+(1-t) p$. Then, $y_{t} \in C$ and hence

$$
0 \geq-\left\langle B y_{n}, y_{t}-u_{n}\right\rangle-\left\langle y_{t}-u_{n}, \frac{J u_{n}-J y_{n}}{r_{n}}\right\rangle+f\left(y_{t}, u_{n}\right), \quad \forall y_{t} \in C .
$$

It follows that

$$
\begin{aligned}
\left\langle B y_{t}, y_{t}-u_{n}\right\rangle \geq & \left\langle B y_{t}, y_{t}-u_{n}\right\rangle-\left\langle B y_{n}, y_{t}-u_{n}\right\rangle-\left\langle y_{t}-u_{n}, \frac{J u_{n}-J \gamma_{n}}{r_{n}}\right\rangle+f\left(y_{t}, u_{n}\right), \quad \forall y_{t} \in C \\
= & \left\langle B y_{t}, y_{t}-u_{n}\right\rangle-\left\langle B u_{n}, y_{t}-u_{n}\right\rangle+\left\langle B u_{n}, y_{t}-u_{n}\right\rangle \\
& -\left\langle B y_{n}, y_{t}-u_{n}\right\rangle-\left\langle y_{t}-u_{n}, \frac{u_{n}-J y_{n}}{r_{n}}\right\rangle+f\left(y_{t}, u_{n}\right), \quad \forall y_{t} \in C \\
= & \left\langle B y_{t}-B u_{n}, y_{t}-u_{n}\right\rangle+\left\langle B u_{n}-B y_{n}, y_{t}-u_{n}\right\rangle-\left\langle y_{t}-u_{n}, \frac{J u_{n}-\gamma_{n}}{r_{n}}\right\rangle+f\left(y_{t}, u_{n}\right), \quad \forall y_{t} \in C .
\end{aligned}
$$


By the continuity of $B$, J, and from (3.22) and (3.23), we obtain that $B u_{n}-B y_{n} \rightarrow 0$ as $n \rightarrow \infty$. From $r_{n}>0$ then $\frac{\left\|u_{n}-J y_{n}\right\|}{r_{n}} \rightarrow 0$ as $n \rightarrow \infty$. Since $B$ is monotone, we know that $\left\langle B y_{t}-B u_{n}, y_{t}-u_{n}\right\rangle \geq 0$. Thus, it follows from (A4) that

$$
\begin{aligned}
f\left(y_{t}, p\right) & \leq \lim _{n \rightarrow \infty} \inf f\left(y_{t}, u_{n}\right) \\
& \leq \lim _{n \rightarrow \infty}\left\langle B y_{t}, y_{t}-u_{n}\right\rangle \\
& =\left\langle B y_{t}, y_{t}-p\right\rangle .
\end{aligned}
$$

From the conditions (A1) and (A4) we have

$$
\begin{aligned}
0 & =f\left(y_{t}, y_{t}\right) \\
& \leq t f\left(y_{t}, y\right)+(1-t) f\left(y_{t}, p\right) \\
& \leq t f\left(y_{t}, y\right)+(1-t)\left\langle B y_{t}, y_{t}-p\right\rangle \\
& \leq t f\left(y_{t}, y\right)+(1-t) t\left\langle B y_{t}, y-p\right\rangle,
\end{aligned}
$$

and hence

$$
0 \leq f\left(y_{t}, y\right)+(1-t)\left\langle B y_{t}, y-p\right\rangle .
$$

Letting $t \rightarrow 0$, we have

$$
0 \leq f(p, y)+\langle B p, y-p\rangle, \quad \forall y \in C .
$$

This implies that $p \in \operatorname{GEP}(f, B)$.

(b) We show that $p \in \cap_{i=1}^{\infty} F\left(S_{i}\right)$. From (3.4) and (3.8), for $q \in F$, we have

$$
\lim _{n \rightarrow \infty} \phi\left(q, y_{n}\right)=\phi(q, p)
$$

We note that

$$
\begin{aligned}
\phi\left(u_{n}, z_{n}\right)= & \phi\left(T_{r_{n}} y_{n}, z_{n}\right) \\
\leq & \phi\left(q, x_{n}\right)-\phi\left(q, T_{r_{n}} y_{n}\right) \\
\leq & \phi\left(q, x_{n}\right)-\phi\left(q, y_{n}\right) \\
& \rightarrow 0 \text { as } n \rightarrow \infty .
\end{aligned}
$$

From Lemma 2.3, we get

$$
\lim _{n \rightarrow \infty}\left\|u_{n}-z_{n}\right\|=0
$$

By using the triangle inequality, we have

$$
\left\|x_{n}-z_{n}\right\| \leq\left\|x_{n}-u_{n}\right\|+\left\|u_{n}-z_{n}\right\| .
$$

It follows from (3.19) and (3.26) that

$$
\lim _{n \rightarrow \infty}\left\|x_{n}-z_{n}\right\|=0,
$$

and $J$ is uniformly norm-to-norm continuous, we also have

$$
\lim _{n \rightarrow \infty}\left\|J z_{n}-J x_{n}\right\|=0 .
$$

By using the triangle inequality, we obtain

$$
\left\|x_{n+1}-y_{n}\right\| \leq\left\|x_{n+1}-u_{n}\right\|+\left\|u_{n}-y_{n}\right\| .
$$


By (3.18) and (3.22), we get

$$
\lim _{n \rightarrow \infty}\left\|x_{n+1}-y_{n}\right\|=0 .
$$

Since $J$ is uniformly norm-to-norm continuous, we obtain

$$
\lim _{n \rightarrow \infty}\left\|J x_{n+1}-J y_{n}\right\|=0 .
$$

From (3.3), we note that

$$
\begin{aligned}
\left\|J x_{n+1}-J y_{n}\right\| & =\left\|J x_{n+1}-\left(\alpha_{n, 0} J x_{n}+\sum_{i=1}^{\infty} \alpha_{n, i} J S_{i}^{n} z_{n}\right)\right\| \\
& =\left\|\alpha_{n, 0} J x_{n+1}-\alpha_{n, 0} J x_{n}+\sum_{i=1}^{\infty} \alpha_{n, i} J x_{n+1}-\sum_{i=1}^{\infty} \alpha_{n, j} J S_{i}^{n} z_{n}\right\| \\
& =\left\|\alpha_{n, 0}\left(J x_{n+1}-J x_{n}\right)+\sum_{i=1}^{\infty} \alpha_{n, i}\left(J x_{n+1}-J S_{i}^{n} z_{n}\right)\right\| \\
& =\left\|\sum_{i=1}^{\infty} \alpha_{n, i}\left(J x_{n+1}-J S_{i}^{n} z_{n}\right)-\alpha_{n, 0}\left(J x_{n}-J x_{n+1}\right)\right\| \\
& \geq \sum_{i=1}^{\infty} \alpha_{n, i}\left\|J x_{n+1}-J S_{i}^{n} z_{n}\right\|-\alpha_{n, 0}\left\|J x_{n}-J x_{n+1}\right\|,
\end{aligned}
$$

and hence

$$
\left\|J x_{n+1}-J S_{i}^{n} z_{n}\right\| \leq \frac{1}{\sum_{i=1}^{\infty} \alpha_{n, i}}\left(\left\|J x_{n+1}-J y_{n}\right\|+\alpha_{n, 0}\left\|J x_{n}-J x_{n+1}\right\|\right) .
$$

From (3.16), (3.31), and $\lim \inf _{n \rightarrow \infty} \sum_{i=1}^{\infty} \alpha_{n, i}>0$, for each $i \geq 1$, we obtain that

$$
\lim _{n \rightarrow \infty}\left\|J x_{n+1}-J S_{i}^{n} z_{n}\right\|=0 .
$$

Since $J^{1}$ is uniformly norm-to-norm continuous on bounded sets, we have

$$
\lim _{n \rightarrow \infty}\left\|x_{n+1}-S_{i}^{n} z_{n}\right\|=0 .
$$

Again by using the triangle inequality, for each $i \geq 1$, we get

$$
\left\|z_{n}-S_{i}^{n} z_{n}\right\| \leq\left\|z_{n}-x_{n}\right\|+\left\|x_{n}-x_{n+1}\right\|+\left\|x_{n+1}-S_{i}^{n} z_{n}\right\| .
$$

From (3.15), (3.27), and (3.34), for each $i \geq 1$, it follows that

$$
\lim _{n \rightarrow \infty}\left\|z_{n}-S_{i}^{n} z_{n}\right\|=0 .
$$

Since $\lim _{n \rightarrow \infty}|| x_{n}-z_{n} \|=0$ and $x_{n} \rightarrow p$ as $n \rightarrow \infty$, imply that $z_{n} \rightarrow p$ as $n \rightarrow \infty$. By using the triangle inequality, for each $i \geq 1$

$$
\left\|S_{i}^{n} z_{n}-p\right\| \leq\left\|S_{i}^{n} z_{n}-z_{n}\right\|+\left\|z_{n}-p\right\| .
$$

For each $i \geq 1$, we have

$$
\lim _{n \rightarrow \infty}\left\|S_{i}^{n} z_{n}-p\right\|=0 .
$$

Moreover, by the assumption that for each $i \geq 1, S_{i}$ is uniformly $L_{i}$-Lipschitz continuous, hence we have 


$$
\begin{aligned}
\left\|S_{i}^{n+1} z_{n}-S_{i}^{n} z_{n}\right\| & \leq\left\|S_{i}^{n+1} z_{n}-S_{i}^{n+1} z_{n+1}\right\|+\left\|S_{i}^{n+1} z_{n+1}-z_{n+1}\right\|+\left\|z_{n+1}-z_{n}\right\|+\left\|z_{n}-S_{i}^{n} z_{n}\right\| \\
& \leq\left(L_{i}+1\right)\left\|z_{n+1}-z_{n}\right\|+\left\|S_{i}^{n+1} z_{n+1}-z_{n+1}\right\|+\left\|z_{n}-S_{i}^{n} z_{n}\right\| .
\end{aligned}
$$

By (3.15) and (3.35), it yields that $\left\|S_{i}^{n+1} z_{n}-S_{i}^{n} z_{n}\right\| \rightarrow 0$. From $S_{i}^{n} z_{n} \rightarrow p$, we have $S_{i}^{n+1} z_{n} \rightarrow p$, that is, $S_{i} S_{i}^{n} z_{n} \rightarrow p$. In view of closeness of $S_{i}$, we have $S_{i} p=p$, for all $i \geq$ 1. This imply that $p \in \cap_{i=1}^{\infty} F\left(S_{i}\right)$

(c) We show that $p \in V I(A, C)$. Indeed, define $\mathcal{M} \subset E \times E^{*}$ by

$$
\mathcal{M} v=\left\{\begin{array}{l}
A v+N_{C}(v), \quad v \in C ; \\
\emptyset, \quad v \notin C .
\end{array}\right.
$$

By Lemma 2.10, $\mathcal{M}$ is maximal monotone and $\mathcal{M}^{-1} 0=V I(A, C)$. Let $(v, w) \in G(\mathcal{M})$. Since $w \in \mathcal{M} v=A v+N_{C}(v)$, we get $w-A v \in N_{C}(v)$.

From $z_{n} \in C$, we have

$$
\left\langle v-z_{n}, w-A v\right\rangle \geq 0 .
$$

On the other hand, since $z_{n}=\Pi_{C} J^{-1}\left(J x_{n}-\lambda_{n} A x_{n}\right)$. Then, by Lemma 2.4, we have

$$
\left\langle v-z_{n}, J z_{n}-\left(J x_{n}-\lambda_{n} A x_{n}\right)\right\rangle \geq 0,
$$

and thus

$$
\left\langle v-z_{n}, \frac{J x_{n}-I z_{n}}{\lambda_{n}}-A x_{n}\right\rangle \leq 0
$$

It follows from (3.39) and (3.40) that

$$
\begin{aligned}
\left\langle v-z_{n}, w\right\rangle & \geq\left\langle v-z_{n}, A v\right\rangle \\
& \geq\left\langle v-z_{n}, A v\right\rangle+\left\langle v-z_{n}, \frac{J x_{n}-J z_{n}}{\lambda_{n}}-A x_{n}\right\rangle \\
& =\left\langle v-z_{n}, A v-A x_{n}\right\rangle+\left\langle v-z_{n}, \frac{J x_{n}-J z_{n}}{\lambda_{n}}\right\rangle \\
& =\left\langle v-z_{n}, A v-A z_{n}\right\rangle+\left\langle v-z_{n}, A z_{n}-A x_{n}\right\rangle+\left\langle v-z_{n}, \frac{J x_{n}-J z_{n}}{\lambda_{n}}\right\rangle \\
& \geq-\left\|v-z_{n}\right\| \frac{\left\|z_{n}-x_{n}\right\|}{\alpha}-\left\|v-z_{n}\right\| \frac{\left\|x_{n}-J z_{n}\right\|}{a} \\
& \geq-M\left(\frac{\left\|z_{n}-x_{n}\right\|}{\alpha}+\frac{\left\|x_{n}-J z_{n}\right\|}{a}\right),
\end{aligned}
$$

where $M=\sup _{n \geq 1}\left\|v-z_{n}\right\|$. Take the limit as $n \rightarrow \infty$ and (3.28), we obtain $\langle v-p, w\rangle$ $\geq 0$. By the maximality of $\mathcal{M}$, we have $p \in \mathcal{M}^{-1} 0$, that is, $p \in V I(A, C)$.

Finally, we show that $p=\Pi_{F} x_{0}$. From $x_{n}=\Pi_{C_{n}} x_{0}$, we have $\left\langle J x_{0}-J x_{n}, x_{n}-z\right\rangle \geq 0, \forall z \in$ $C_{n}$. Since $F \subset C_{n}$, we also have

$$
\left\langle J x_{0}-J x_{n}, x_{n}-y\right\rangle \geq 0, \quad \forall y \in F .
$$

Taking limit $n \rightarrow \infty$, we obtain

$$
\left\langle J x_{0}-J p, p-y\right\rangle \geq 0, \quad \forall y \in F .
$$

By Lemma 2.4, we can conclude that $p=\Pi_{F} x_{0}$ and $x_{n} \rightarrow p$ as $n \rightarrow \infty$. This completes the proof. $\square$

If $S_{i}=S$ for each $i \in \mathbb{N}$, then Theorem 3.2 is reduced to the following corollary.

Corollary 3.3. Let $C$ be a nonempty closed and convex subset of a 2-uniformly convex and uniformly smooth Banach space $E$. Let $A$ be an $\alpha$-inverse-strongly monotone mapping of $C$ into $E^{*}$ satisfying $\|A y\| \leq\|A y-A u\|, \forall y \in C$ and $u \in V I(A, C) \neq \varnothing$. Let $f$ 
be a bifunction from $C \times C$ to $\mathbb{R}$ satisfying (A1)-(A4) and $B$ be a continuous monotone mapping of $C$ into $E^{*}$. Let $S: C \rightarrow C$ be a closed uniformly L-Lipschitz continuous and quasi- $\phi$-asymptotically nonexpansive mappings with a sequence $\left\{k_{n}\right\} \subset[1, \infty), k_{n} \rightarrow 1$ such that $F:=F(S) \cap G E P(f, B) \cap V I(A, C)$ is a nonempty and bounded subset in $C$. For an initial point $x_{0} \in E$ with $x_{1}=\Pi_{C_{1}} x_{0}$ and $C_{1}=C$, we define the sequence $\left\{x_{n}\right\}$ as follows:

$$
\left\{\begin{array}{l}
z_{n}=\Pi_{C} J^{-1}\left(J x_{n}-\lambda_{n} A x_{n}\right) \\
y_{n}=J^{-1}\left(\alpha_{n} J x_{n}+\left(1-\alpha_{n}\right) J S^{n} z_{n}\right) \\
f\left(u_{n}, y\right)+\left\langle B y_{n}, y-u_{n}\right\rangle+\frac{1}{r_{n}}\left\langle y-u_{n}, J u_{n}-J y_{n}\right\rangle \geq 0, \quad \forall y \in C, \\
C_{n+1}=\left\{z \in C_{n}: \phi\left(z, u_{n}\right) \leq \phi\left(z, x_{n}\right)+\zeta_{n}\right\} \\
x_{n+1}=\Pi_{C_{n+1}} x_{0}, \quad \forall n \geq 1
\end{array}\right.
$$

where $\zeta_{n}=\sup _{q \in F}\left(k_{n}-1\right) \phi\left(q, x_{n}\right),\left\{\alpha_{n}\right\}$ is sequence in $[0,1],\left\{r_{n}\right\} \subset[d, \infty)$ for some $d$ $>0$ and $\left\{\lambda_{n}\right\} \subset[a, b]$ for some $a, b$ with $0<a<b<c^{2} \alpha / 2$, where $\frac{1}{c}$ is the 2-uniformly convexity constant of $E$. If $\lim \inf _{n \rightarrow \infty} \alpha_{n}\left(1-\alpha_{n}\right)>0$, then $\left\{x_{n}\right\}$ converges strongly to $p \in$ $F$, where $p=\Pi_{F} x_{0}$.

For a special case that $i=1,2$, we can obtain the following results on a pair of quasi$\phi$-asymptotically nonexpansive mappings immediately from Theorem 3.2.

Corollary 3.4. Let $C$ be a nonempty closed and convex subset of a 2-uniformly convex and uniformly smooth Banach space $E$. Let $A$ be an $\alpha$-inverse-strongly monotone mapping of $C$ into $E^{*}$ satisfying $\|A y\| \leq\|A y-A u\|, \forall y \in C$ and $u \in V I(A, C) \neq \varnothing$. Let $f$ be a bifunction from $C \times C$ to $\mathbb{R}$ satisfying (A1)-(A4) and $B$ be a continuous monotone mapping of $C$ into $E^{*}$. Let $S, T: C \rightarrow C$ be two closed quasi- $\phi$-asymptotically nonexpansive mappings and uniformly $L_{S}, L_{T}$-Lipschitz continuous, respectively, with a sequence $\left\{k_{n}\right\} \subset[1, \infty), k_{n} \rightarrow 1$ such that $F:=F(S) \cap F(T) \cap G E P(f, B) \cap V I(A, C)$ is a nonempty and bounded subset in $C$. For an initial point $x_{0} \in E$ with $x_{1}=\Pi_{C_{1}} x_{0}$ and $C_{1}=C$, we define the sequence $\left\{x_{n}\right\}$ as follows:

$$
\left\{\begin{array}{l}
z_{n}=\Pi_{C} J^{-1}\left(J x_{n}-\lambda_{n} A x_{n}\right) \\
y_{n}=J^{-1}\left(\alpha_{n} J x_{n}+\beta_{n} J S^{n} z_{n}+\gamma_{n} J T^{n} z_{n}\right) \\
f\left(u_{n}, y\right)+\left\langle B y_{n}, y-u_{n}\right\rangle+\frac{1}{r_{n}}\left\langle y-u_{n}, J u_{n}-J y_{n}\right\rangle \geq 0, \quad \forall y \in C, \\
C_{n+1}=\left\{z \in C_{n}: \phi\left(z, u_{n}\right) \leq \phi\left(z, x_{n}\right)+\zeta_{n}\right\} \\
x_{n+1}=\Pi_{C_{n+1}} x_{0}, \quad \forall n \geq 1
\end{array}\right.
$$

where $\zeta_{n}=\sup _{q \in F}\left(k_{n}-1\right) \phi\left(q, x_{n}\right),\left\{\alpha_{n}\right\},\left\{\beta_{n}\right\}$ and $\left\{\gamma_{n}\right\}$ are sequences in $[0,1],\left\{r_{n}\right\} \subset$ $[d, \infty)$ for some $d>0$ and $\left\{\lambda_{n}\right\} \subset[a, b]$ for some $a, b$ with $0<a<b<c^{2} \alpha / 2$, where $\frac{1}{c}$ is the 2-uniformly convexity constant of $E$. If $\alpha_{n}+\beta_{n}+\gamma_{n}=1$ for all $n \geq 0$ and $\lim$ $\inf _{n \rightarrow \infty} \alpha_{n} \beta_{n}>0$ and lim inf $\ln _{n \rightarrow \infty} \alpha_{n} \gamma_{n}>0$, then $\left\{x_{n}\right\}$ converges strongly to $p \in F$, where $p=\Pi_{F} x_{0}$.

Corollary 3.5. Let $C$ be a nonempty closed and convex subset of a 2-uniformly convex and uniformly smooth Banach space E. Let $A$ be an $\alpha$-inverse-strongly monotone mapping of $C$ into $E^{*}$ satisfying $\|A y\| \leq\|A y-A u\|, \forall y \in C$ and $u \in V I(A, C) \neq \varnothing$. Let $f$ be a bifunction from $C \times C$ to $\mathbb{R}$ satisfying (A1)-(A4) and $B$ be a continuous monotone mapping of $C$ into $E^{*}$. Let $\left\{S_{i}\right\}_{i=1}^{\infty}: C \rightarrow C b e$ an infinite family of closed quasi- $\phi$-nonexpansive mappings such that $F:=\cap_{i=1}^{\infty} F\left(S_{i}\right) \cap \operatorname{GEP}(f, B) \cap V I(A, C) \neq \emptyset$.For an initial point $x_{0} \in E$ with $x_{1}=\Pi_{C_{1}} x_{0}$ and $C_{1}=C$, we define the sequence $\left\{x_{n}\right\}$ as follows: 


$$
\left\{\begin{array}{l}
z_{n}=\Pi_{C} J^{-1}\left(J x_{n}-\lambda_{n} A x_{n}\right) \\
y_{n}=J^{-1}\left(\alpha_{n, 0} J x_{n}+\sum_{i=1}^{\infty} \alpha_{n, i} J S_{i} z_{n}\right) \\
f\left(u_{n}, y\right)+\left\langle B y_{n}, y-u_{n}\right\rangle+\frac{1}{r_{n}}\left\langle y-u_{n}, J u_{n}-J y_{n}\right\rangle \geq 0, \quad \forall y \in C \\
C_{n+1}=\left\{z \in C_{n}: \phi\left(z, u_{n}\right) \leq \phi\left(z, x_{n}\right)\right\} \\
x_{n+1}=\prod_{C_{n+1}} x_{0}, \quad \forall n \geq 1
\end{array}\right.
$$

where $\left\{\alpha_{n, i}\right\}$ is sequence in $[0,1],\left\{r_{n}\right\} \subset[d, \infty)$ for some $d>0$ and $\left\{\lambda_{n}\right\} \subset[a, b]$ for some $a, b$ with $0<a<b<c^{2} \alpha / 2$, where $\frac{1}{c}$ is the 2-uniformly convexity constant of $E$. If $\sum_{i=0}^{\infty} \alpha_{n, i}=1$ for all $n \geq 0$ and $\lim _{\inf _{n \rightarrow \infty}} \alpha_{n, 0} \alpha_{n, i}>0$ for all $i \geq 1$, then $\left\{x_{n}\right\}$ converges strongly to $p \in F$, where $p=\Pi_{F} x_{0}$.

Proof Since $\left\{S_{i}\right\}_{i=1}^{\infty}: C \rightarrow C$ is an infinite family of closed quasi- $\phi$-nonexpansive mappings, it is an infinite family of closed and uniformly quasi- $\phi$-asymptotically nonexpansive mappings with sequence $k_{n}=1$. Hence, the conditions appearing in Theorem 3.2 $F$ is a bounded subset in $C$ and for each $i \geq 1, S_{i}$ is uniformly $L_{i}$-Lipschitz continuous are of no use here. By virtue of the closeness of mapping $S_{i}$ for each $i \geq 1$, it yields that $p \in F\left(S_{i}\right)$ for each $i \geq 1$, that is, $p \in \cap_{i=1}^{\infty} F\left(S_{i}\right)$. Therefore, all the conditions in Theorem 3.2 are satisfied. The conclusion of Corollary 3.5 is obtained from Theorem 3.2 immediately.

Corollary 3.6. [39, Theorem 3.2] Let $C$ be a nonempty closed and convex subset of a 2-uniformly convex and uniformly smooth Banach space E. Let $A$ be an $\alpha$-inversestrongly monotone mapping of $C$ into $E^{*}$ satisfying $\|A y\| \leq\|A y-A u\|, \forall y \in C$ and $u$ $\in V I(A, C) \neq \varnothing$. Let $f$ be a bifunction from $C \times C$ to $\mathbb{R}$ satisfying (A1)-(A4) and $B$ be a continuous monotone mapping of $C$ into $E^{*}$. Let $\left\{S_{i}\right\}_{i=1}^{N}: C \rightarrow$ Cbe a finite family of closed quasi-申-nonexpansive mappings such that $F:=\cap_{i=1}^{N} F\left(S_{i}\right) \cap \operatorname{GEP}(f, B) \cap \operatorname{VI}(A, C) \neq \emptyset$. For an initial point $x_{0} \in E$ with $x_{1}=\Pi_{C_{1}} x_{0}$ and $C 1=C$, we define the sequence $\left\{x_{n}\right\}$ as follows:

$$
\left\{\begin{array}{l}
z_{n}=\Pi_{C} J^{-1}\left(J x_{n}-\lambda_{n} A x_{n}\right), \\
y_{n}=J^{-1}\left(\alpha_{n, 0} J x_{n}+\sum_{i=1}^{N} \alpha_{n, i} J S_{i} z_{n}\right), \\
f\left(u_{n}, y\right)+\left\langle B y_{n}, y-u_{n}\right\rangle+\frac{1}{r_{n}}\left\langle y-u_{n}, J u_{n}-J y_{n}\right\rangle \geq 0, \quad \forall y \in C, \\
C_{n+1}=\left\{z \in C_{n}: \phi\left(z, u_{n}\right) \leq \phi\left(z, x_{n}\right)\right\} \\
x_{n+1}=\Pi_{C_{n+1}} x_{0}, \quad \forall n \geq 1,
\end{array}\right.
$$

where $\left\{\alpha_{n, i}\right\}$ is sequence in $[0,1],\left\{r_{n}\right\} \subset[d, \infty)$ for some $d>0$ and $\left\{\lambda_{n}\right\} \subset[a, b]$ for some $a, b$ with $0<a<b<c^{2} \alpha / 2$, where $\frac{1}{c}$ is the 2-uniformly convexity constant of $E$. If $\alpha_{i} \in(0,1)$ such that $\sum_{i=0}^{N} \alpha_{i}=1$, then $\left\{x_{n}\right\}$ converges strongly to $p \in F$, where $p=\Pi_{F} x_{0}$.

Remark 3.7. Theorem 3.2, Corollaries 3.5 and 3.6 improve and extend the corresponding results in Wattanawitoon and Kumam [34] and Zegeye [39] in the following senses:

- from a solution of the classical equilibrium problem to the generalized equilibrium problem with an infinite family of quasi- $\phi$-asymptotically mappings;

- for the mappings, we extend the mappings from nonexpansive mappings, relatively quasi-nonexpansive mappings or quasi- $\phi$-nonexpansive mappings and a finite family of closed relatively quasi-nonexpansive mappings to an infinite family of quasi- $\phi$-asymptotically nonexpansive mappings. 


\section{Deduced theorems}

Corollary 4.1. Let $C$ be a nonempty closed and convex subset of a uniformly convex and uniformly smooth Banach space $E$. Let $f$ be a bifunction from $C \times C$ to $\mathbb{R}$ satisfying (A1)-(A4). Let B be a continuous monotone mapping of $C$ into $E^{*}$. Let $\left\{S_{i}\right\}_{i=1}^{\infty}: C \rightarrow C b e$ an infinite family of closed and uniformly quasi- $\phi$-asymptotically nonexpansive mappings with a sequence $\left\{k_{n}\right\} \subset[1, \infty), k_{n} \rightarrow 1$ and uniformly $L_{i}$-Lipschitz continuous such that $F:=\cap_{i=1}^{\infty} F\left(S_{i}\right) \cap \operatorname{GEP}(f, B)$ is a nonempty and bounded subset in $C$. For an initial point $x_{0} \in E$ with $x_{1}=\Pi_{C_{1}} x_{0}$ and $C_{1}=C$, we define the sequence $\left\{x_{n}\right\}$ as follows:

$$
\left\{\begin{array}{l}
y_{n}=J^{-1}\left(\alpha_{n, 0} J x_{n}+\sum_{i=1}^{\infty} \alpha_{n, i} J S_{i}^{n} x_{n}\right), \\
f\left(u_{n}, y\right)+\left\langle B y_{n}, y-u_{n}\right\rangle+\frac{1}{r_{n}}\left\langle y-u_{n}, J u_{n}-J y_{n}\right\rangle \geq 0, \quad \forall y \in C, \\
C_{n+1}=\left\{z \in C_{n}: \phi\left(z, u_{n}\right) \leq \phi\left(z, x_{n}\right)+\zeta_{n}\right\}, \\
x_{n+1}=\prod_{C_{n+1}} x_{0}, \quad \forall n \geq 0,
\end{array}\right.
$$

where $\zeta_{n}=\sup _{q \in F}\left(k_{n}-1\right) \phi\left(q, x_{n}\right),\left\{\alpha_{n, i}\right\}$ is sequence in $[0,1],\left\{r_{n}\right\} \subset[a, \infty)$ for some a $>0$. If $\sum_{i=0}^{\infty} \alpha_{n, i}=1$ for all $n \geq 0$ and $\lim _{\inf _{n \rightarrow \infty}} \alpha_{n, 0} \alpha_{n, i}>0$ for all $i \geq 1$, then $\left\{x_{n}\right\}$ converges strongly to $p \in F$, where $p=\Pi_{F} x_{0}$.

Proof Put $A \equiv 0$ in Theorem 3.2. Then, we get that $z_{n}=x_{n}$. Thus, the method of proof of Theorem 3.2 gives the required assertion without the requirement that $E$ be 2-uniformly convex.

If setting $B \equiv 0$ in Corollary 4.1, then we have the following corollary.

Corollary 4.2. Let $C$ be a nonempty closed and convex subset of a uniformly convex and uniformly smooth Banach space $E$. Let $f$ be a bifunction from $C \times C$ to $\mathbb{R}$ satisfying (A1)-(A4). Let $\left\{S_{i}\right\}_{i=1}^{\infty}: C \rightarrow$ Cbe an infinite family of closed and uniformly quasi$\phi$-asymptotically nonexpansive mappings with a sequence $\left\{k_{n}\right\} \subset[1, \infty), k_{n} \rightarrow 1$ and uniformly $L_{i}$-Lipschitz continuous such that $F:=\cap_{i=1}^{\infty} F\left(S_{i}\right) \cap E P(f)$ is a nonempty and bounded subset in $C$. For an initial point $x_{0} \in E$ with $x_{1}=\Pi_{C_{1}} x_{0}$ and $C_{1}=C$, we define the sequence $\left\{x_{n}\right\}$ as follows:

$$
\left\{\begin{array}{l}
y_{n}=J^{-1}\left(\alpha_{n, 0} J x_{n}+\sum_{i=1}^{\infty} \alpha_{n, i} J S_{i}^{n} x_{n}\right), \\
f\left(u_{n}, y\right)+\frac{1}{r_{n}}\left\langle y-u_{n} J u_{n}-J y_{n}\right\rangle \geq 0, \quad \forall y \in C, \\
C_{n+1}=\left\{z \in C_{n}: \phi\left(z, u_{n}\right) \leq \phi\left(z, x_{n}\right)+\zeta_{n}\right\}, \\
x_{n+1}=\Pi_{C_{n+1}} x_{0}, \quad \forall n \geq 0,
\end{array}\right.
$$

where $\zeta_{n}=\sup _{q \in F}\left(k_{n}-1\right) \phi\left(q, x_{n}\right),\left\{\alpha_{n, i}\right\}$ is sequence in $[0,1],\left\{r_{n}\right\} \subset[a, \infty)$ for some a $>0$. If $\sum_{i=0}^{\infty} \alpha_{n, i}=1$ for all $n \geq 0$ and $\lim _{\inf _{n \rightarrow \infty}} \alpha_{n, 0} \alpha_{n, i}>0$ for all $i \geq 1$, then $\left\{x_{n}\right\}$ converges strongly to $p \in F$, where $p=\Pi_{F} x_{0}$.

If setting $f \equiv 0$ in Corollary 4.1, then we obtain the following corollary.

Corollary 4.3. Let $C$ be a nonempty closed and convex subset of a uniformly convex and uniformly smooth Banach space E. Let $B$ be a continuous monotone mapping of $C$ into $E^{*}$. Let $\left\{S_{i}\right\}_{i=1}^{\infty}: C \rightarrow$ Cbe an infinite family of closed and uniformly quasi- $\phi$-asymptotically nonexpansive mappings with a sequence $\left\{k_{n}\right\} \subset[1, \infty), k_{n} \rightarrow 1$ and uniformly $L_{i}$-Lipschitz continuous such that $F:=\cap_{i=1}^{\infty} F\left(S_{i}\right) \cap V I(B, C)$ is a nonempty and bounded subset in C. For an initial point $x_{0} \in E$ with $x_{1}=\Pi_{C_{1}} x_{0}$ and $C_{1}=C$, we define the sequence $\left\{x_{n}\right\}$ as follows: 


$$
\left\{\begin{array}{l}
y_{n}=J^{-1}\left(\alpha_{n, 0} J x_{n}+\sum_{i=1}^{\infty} \alpha_{n, i} J S_{i}^{n} z_{n}\right), \\
\left\langle B y_{n}, y-u_{n}\right\rangle+\frac{1}{r_{n}}\left\langle y-u_{n}, J u_{n}-J y_{n}\right\rangle \geq 0, \quad \forall y \in C_{,} \\
C_{n+1}=\left\{z \in C_{n}: \phi\left(z, u_{n}\right) \leq \phi\left(z, x_{n}\right)+\zeta_{n}\right\} \\
x_{n+1}=\prod_{C_{n+1}} x_{0}, \quad \forall n \geq 0,
\end{array}\right.
$$

where $\zeta_{n}=\sup _{q \in F}\left(k_{n}-1\right) \phi\left(q, x_{n}\right),\left\{\alpha_{n, i}\right\}$ is sequence in $[0,1],\left\{r_{n}\right\} \subset[a, \infty)$ for some a $>0$. If $\sum_{i=0}^{\infty} \alpha_{n, i}=1$ for all $n \geq 0$ and $\lim _{\inf _{n \rightarrow \infty}} \alpha_{n, 0} \alpha_{n, i}>0$ for all $i \geq 1$, then $\left\{x_{n}\right\}$ converges strongly to $p \in F$, where $p=\prod_{F} x_{0}$.

Remark 4.4. Corollaries 4.1 $\{4.3$ improve and extend the corresponding results in Zegeye [39] and Wattanawitoon and Kumam [34] in the sense from a finite family of closed relatively quasi-nonexpansive mappings and closed relatively quasi-nonexpansive mappings to more general than an infinite family of closed and uniformly quasi$\phi$-asymptotically nonexpansive mappings.

\section{Application to Hilbert spaces}

If $E=H$, a Hilbert space, then $E$ is 2-uniformly convex (we can choose $c=1$ ) and uniformly smooth real Banach space and closed relatively quasi-nonexpansive map reduces to closed quasi-nonexpansive map. Moreover, $J=I$, identity operator on $H$ and $\Pi_{C}=P_{C}$, projection mapping from $H$ into $C$. Thus, the following corollaries hold.

Theorem 5.1. Let $C$ be a nonempty closed and convex subset of a Hilbert space $H$. Let $f$ be a bifunction from $C \times C$ to $\mathbb{R}$ satisfying (A1)-(A4). Let $A$ be an $\alpha$-inversestrongly monotone mapping of $C$ into $H$ satisfying $\|A y\| \leq\|A y-A u\|, \forall y \in C$ and $u$ $\in V I(A, C) \neq \varnothing$ and $B$ be a continuous monotone mapping of $C$ into $H$. Let $\left\{S_{i}\right\}_{i=1}^{\infty}: C \rightarrow$ Cbe an infinite family of closed and uniformly quasi- $\phi$-asymptotically nonexpansive mappings with a sequence $\left\{k_{n}\right\} \subset[1, \infty), k_{n} \rightarrow 1$ and uniformly $L_{i^{-}}$ Lipschitz continuous such that $F:=\cap_{i=1}^{\infty} F\left(S_{i}\right) \cap \operatorname{GEP}(f, B) \cap V I(A, C)$ is a nonempty and bounded subset in $C$. For an initial point $x_{0} \in H$ with $x_{1}=\Pi_{C_{1}} x_{0}$ and $C_{1}=C$, we define the sequence $\left\{x_{n}\right\}$ as follows:

$$
\left\{\begin{array}{l}
z_{n}=P_{C}\left(x_{n}-\lambda_{n} A x_{n}\right), \\
y_{n}=\alpha_{n, 0} x_{n}+\sum_{i=1}^{\infty} \alpha_{n, i} S_{i}^{n} z_{n} \\
f\left(u_{n}, y\right)+\left\langle B y_{n}, y-u_{n}\right\rangle+\frac{1}{r_{n}}\left\langle y-u_{n}, u_{n}-y_{n}\right\rangle \geq 0, \quad \forall y \in C, \\
C_{n+1}=\left\{z \in C_{n}:\left\|z-u_{n}\right\| \leq\left\|z-x_{n}\right\|+\zeta_{n}\right\} \\
x_{n+1}=P_{C_{n+1}} x_{0}, \quad \forall n \geq 0,
\end{array}\right.
$$

where $\zeta_{n}=\sup _{q \in F}\left(k_{n}-1\right)\left\|q-x_{n}\right\|,\left\{\alpha_{n, i}\right\}$ is sequence in $[0,1],\left\{r_{n}\right\} \subset[a, \infty)$ for some $a>0$ and $\left\{\lambda_{n}\right\} \subset[a, b]$ for some $a, b$ with $0<a<b<\alpha / 2$. If $\sum_{i=0}^{\infty} \alpha_{n, i}=1$ for all $n \geq 0$ and $\lim \inf _{n \rightarrow \infty} \alpha_{n, 0} \alpha_{n, i}>0$ for all $i \geq 1$, then $\left\{x_{n}\right\}$ converges strongly to $p \in F$, where $p$ $=\prod_{F} x_{0}$.

Remark 5.2. Theorem 5.1 improve and extend the Corollary 3.7 in Zegeye [39] in the aspect for the mappings, we extend the mappings from a finite family of closed relatively quasi-nonexpansive mappings to more general an infinite family of closed and uniformly quasi- $\phi$-asymptotically nonexpansive mappings.

\section{Acknowledgements}

Ms. Siwaporn Saewan would like to thank the Office of the Higher Education Commission, Thailand, for supporting by grant found under the program Strategic Scholarships for Frontier Research Network for the Join Ph.D. Program Thai Doctoral degree for this research. I thank Dr. Poom Kumam for clarifying several points in my research. Moreover, this research was supported by the Center of Excellence in Mathematics, the Commission on Higher Education, Thailand (under the Project no. RG-1-54-02-1) 


\section{Author details}

'Department of Mathematics, Faculty of Science, King Mongkut's University of Technology Thonburi (KMUTT) Bangmod, Bangkok 10140, Thailand ${ }^{2}$ Centre of Excellence in Mathematics, CHE, Si Ayutthaya Rd., Bangkok 10400, Thailand

\section{Authors' contributions}

All authors contributed equally and significantly in writing this paper. All authors read and approved the final manuscript.

\section{Competing interests}

The authors declare that they have no completing interests.

Received: 28 June 2011 Accepted: 27 October 2011 Published: 27 October 2011

\section{References}

1. Blum, E, Oettli, W: From optimization and variational inequalities to equilibrium problems. Math Student. 63, 123-145 (1994)

2. Klin-eam, C, Suantai, S, Takahashi, W: Strong convergence of generalized projection algorithms for nonlinear operator. Abstr Appl Anal 2009, 18 (2009). Article ID 649831

3. Combettes, PL, Hirstoaga, SA: Equilibrium programming in Hilbert spaces. J Nonlinear Convex Anal. 6, 117-136 (2005)

4. Jaiboon, C, Kumam, P: A general iterative method for solving equilibrium problems, variational inequality problems and fixed point problems of an infinite family of nonexpansive mappings. J Appl Math Comput. 34, 407-439 (2010). doi:10.1007/s12190-009-0330-x

5. Katchang, P, Kumam, P: A new iterative algorithm of solution for equilibrium problems, variational inequalities and fixed point problems in a Hilbert space. J Appl Math Comput. 32, 19-38 (2010). doi:10.1007/s12190-009-0230-0

6. Kim, JK: Strong convergence theorems by hybrid projection methods for equilibrium problems and fixed point problems of the asymptotically quasi-\$phi\$-nonexpansive mappings. Fixed Point Theory Appl. 2011, 10 (2011). doi:10.1186/1687-1812-2011-10

7. Kumam, P: A new hybrid iterative method for solution of equilibrium problems and fixed point problems for an inverse strongly monotone operator and a nonexpansive mapping. J Appl Math Comput. 29, 263-280 (2009). doi:10.1007/ s12190-008-0129-1

8. Moudafi, A: Second-order differential proximal methods for equilibrium problems. J Inequal Pure Appl Math 4(1) (2003). (art.18)

9. Qin, X, Cho, YJ, Kang, SM: Convergence theorems of common elements for equilibrium problems and fixed point problems in Banach spaces. J Comput Appl Math. 225, 20-30 (2009). doi:10.1016/j.cam.2008.06.011

10. Qin, X, Cho, SY, Kang, SM: Strong convergence of shrinking projection methods for quasi-\$\phi\$ -nonexpansive mappings and equilibrium problems. J Comput Appl Math. 234, 750-760 (2010). doi:10.1016/j.cam.2010.01.015

11. Saewan, S, Kumam, P: Modified hybrid block iterative algorithm for convex feasibility problems and generalized equilibrium problems for uniformly quasi-\$phi\$-asymptotically nonexpansive mappings. Abstr Appl Anal 2010, 22 (2010). Article ID 357120

12. Saewan, $S$, Kumam, P: The shrinking projection method for solving generalized equilibrium problem and common fixed points for asymptotically quasi-\$phi\$-nonexpansive mappings. Fixed Point Theory Appl. 2011, 9 (2011). doi:10.1186/ 1687-1812-2011-9

13. Wattanawitoon, K, Kumam, P: Generalized mixed equilibrium problems for maximal monotone operators and two relatively quasi-nonexpansive mappings. Thai J Math. 9, 165-189 (2011)

14. Alber, Yl: Metric and generalized projection operators in Banach spaces: properties and applications. In: Kartsatos AG (ed.) Theory and Applications of Nonlinear Operators of Accretive and Monotone Type. pp. 15-50. Marcel Dekker, New York (1996)

15. Alber, Yl, Reich, S: An iterative method for solving a class of nonlinear operator equations in Banach spaces. Panamer Math J. 4, 39-54 (1994)

16. Cioranescu, I: Geometry of Banach spaces. Duality Mappings and Nonlinear Problems, Kluwer, Dordrecht (1990)

17. Kamimura, S, Takahashi, W: Strong convergence of a proximal-type algorithm in a Banach space. SIAM J Optim. 13, 938-945 (2002). doi:10.1137/S105262340139611X

18. Takahashi, W: Nonlinear Functional Analysis. Yokohama-Publishers, Japan (2000)

19. Reich, S: A weak convergence theorem for the alternating method with Bregman distances. In: Kartsatos AG (ed.) Theory and Applications of Nonlinear Operators of Accretive and Monotone Type. pp. 313-318. Marcel Dekker, New York (1996)

20. Nilsrakoo, W, Saejung, S: Strong convergence to common fixed points of countable relatively quasi-nonexpansive mappings. Fixed Point Theory Appl 2008, 19 (2008). Article ID 312454

21. Su, Y, Wang, D, Shang, M: Strong convergence of monotone hybrid algorithm for hemi-relatively non-expansive mappings. Fixed Point Theory Appl 2008, 8 (2008). Article ID 284613

22. Zegeye, $\mathrm{H}$, Shahzad, $\mathrm{N}$ : Strong convergence for monotone mappings and relatively weak nonexpansive mappings. Nonlinear Anal. 70, 2707-2716 (2009). doi:10.1016/j.na.2008.03.058

23. Butnariu, D, Reich, S, Zaslavski, AJ: Asymptotic behavior of relatively nonexpansive operators in Banach spaces. J Appl Anal. 7, 151-174 (2001). doi:10.1515/JAA.2001.151

24. Butnariu, D, Reich, S, Zaslavski, AJ: Weak convergence of orbits of nonlinear operators in reflexive Banach spaces. Numer Funct Anal Optim. 24, 489-508 (2003). doi:10.1081/NFA-120023869

25. Censor, $Y$, Reich, S: Iterations of paracontractions and firmly nonexpansive operators with applications to feasibility and optimization. Optimization. 37, 323-339 (1996). doi:10.1080/02331939608844225

26. Matsushita, S, Takahashi, W: A strong convergence theorem for relatively nonexpansive mappings in a Banach space. J Approx Theory. 134, 257-266 (2005). doi:10.1016/j.jat.2005.02.007 
27. Saewan, S, Kumam, $\mathrm{P}$, Wattanawitoon, $\mathrm{K}$ : Convergence theorem based on a new hybrid projection method for finding a common solution of generalized equilibrium and variational inequality problems in Banach spaces. Abstr Appl Anal 2010, 26 (2010). Article ID 734126

28. Ball, K, Carlen, EA, Lieb, EH: Sharp uniform convexity and smoothness inequalities for trace norm. Invent Math. 26, 137-150 (1997)

29. Takahashi, Y, Hashimoto, K, Kato, M: On sharp uniform convexity, smoothness, and strong type, cotype inequalities. J Nonlinear Convex Anal. 3, 267-281 (2002)

30. Matsushita, S, Takahashi, W: Weak and strong convergence theorems for relatively nonexpansive mappings in Banach spaces. Fixed Point Theory Appl. 2004, 37-47 (2004)

31. liduka, H, Takahashi, W: Weak convergence of a projection algorithm for variational inequalities in a Banach space. J Math Anal Appl. 339, 668-679 (2008). doi:10.1016/j.jmaa.2007.07.019

32. Takahashi, W, Zembayashi, K: Strong and weak convergence theorems for equilibrium problems and relatively nonexpansive mappings in Banach spaces. Nonlinear Anal. 70, 45-57 (2009). doi:10.1016/j.na.2007.11.031

33. Takahashi, W, Zembayashi, K: Strong convergence theorem by a new hybrid method for equilibrium problems and relatively nonexpansive mappings. Fixed Point Theory Appl 2008, 11 (2008). Article ID 528476

34. Wattanawitoon, K, Kumam, P: A strong convergence theorem by a new hybrid projection algorithm for fixed point problems and equilibrium problems of two relatively quasi-nonexpansive mappings. Nonlinear Anal Hybrid Syst. 3(1):11-20 (2009). doi:10.1016/.nahs.2008.10.002

35. Kohsaka, F, Takahashi, W: Block iterative methods for a finite family of relatively nonexpansive mappings in Banach spaces. Fixed Point Theory Appl 2007, 18 (2007). Article ID 21972

36. Kikkawa, M, Takahashi, W: Approximating fixed points of nonexpansive mappings by the block iterative method in Banach spaces. Int J Comput Numer Anal Appl. 5(1):59-66 (2004)

37. Plubtieng, S, Ungchittrakool, K: Hybrid iterative methods for convex feasibility problems and fixed point problems of relatively nonexpansive mappings in Banach spaces. Fixed Point Theory Appl 2008, 19 (2008). Article ID 583082

38. Chang, SS, Kim, JK, Wang, XR: Modified block iterative algorithm for solving convex feasibility problems in Banach spaces. J Inequal Appl 2010, 14 (2010). Article ID 869684

39. Zegeye, $\mathrm{H}$ : A hybrid iteration scheme for equilibrium problems, variational inequality problems and common fixed point problems in Banach spaces. Nonlinear Anal. 72, 2136-2146 (2010). doi:10.1016/j.na.2009.10.014

40. Beauzamy, B: Introduction to Banach Spaces and their Geometry, 2nd edn. North-Holland, Amsterdam. (1995)

41. Xu, HK: Inequalities in Banach spaces with applications. Nonlinear Anal. 16, 1127-1138 (2009)

42. Zalinescu, C: On uniformly convex functions. J Math Anal Appl. 95, 344-374 (1983). doi:10.1016/0022-247X(83)90112-9

43. Rockafellar, RT: On the maximality of sums of nonlinear monotone operators. Trans Am Math Soc. 149, 75-88 (1970). doi:10.1090/50002-9947-1970-0282272-5

doi:10.1186/1029-242X-2011-96

Cite this article as: Saewan and Kumam: Convergence theorems for uniformly quasi- $\phi$-asymptotically

nonexpansive mappings, generalized equilibrium problems, and variational inequalities. Journal of Inequalities and Applications 2011 2011:96.

\section{Submit your manuscript to a SpringerOpen ${ }^{\odot}$ journal and benefit from:}

- Convenient online submission

- Rigorous peer review

- Immediate publication on acceptance

- Open access: articles freely available online

- High visibility within the field

- Retaining the copyright to your article

Submit your next manuscript at $\boldsymbol{\wedge}$ springeropen.com 